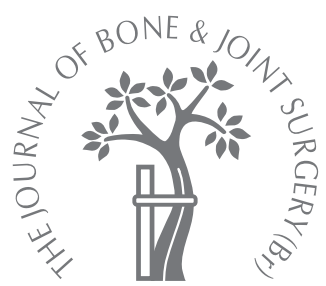

- CASE REPORT

\title{
Adamantinoma of the tibia with late skeletal metastasis
}

\author{
AN UNUSUAL PRESENTATION
}

S. V. Kanakaraddi,

G. Nagaraj,

T. M. Ravinath

From Bapuji

Hospital, Davangere, India
S. V. Kanakaraddi,

MBBS(MS), Post-Graduate Student

II. Nagaraj, MS, Professor, Head of Department

T. M. Ravinath, MS,

Professor

Department of Orthopaedics

J. J. M. Medical College, Bapuji Hospital, Davangere-577004, Karnataka, India.

Correspondence should be sent to $\mathrm{Mr} \mathrm{S}$. V. Kanakaraddi; e-mail: blazedoc1421@yahoo.co.in

(C2007 British Editorial Society of Bone and Joint Surgery doi:10.1302/0301-620X.89B3. $18484 \$ 2.00$

$J$ Bone Joint Surg $[\mathrm{Br}]$ 2007;89-B:388-9.

Received 1 August 2006

Accepted after revision

November 2006

\begin{abstract}
Adamantinoma is a rare tumour of long bones that occurs most commonly in the tibia. Its pathogenesis is unknown. It is locally aggressive and recurrences are common after resection. Metastases have been reported in $10 \%$ to $20 \%$ of cases, most commonly in the lungs and rarely in the lymph nodes. We report a patient who developed a skeletal metastasis four years after resection of the primary tumour. There was no evidence of recurrence at the primary site or of secondary deposits in the lungs.
\end{abstract}

Adamantinoma is a rare tumour of long bones which typically involves the mid-shaft of the tibia; its pathogenesis is unknown. The name derives from its resemblance to ameloblastoma of the jaw. It occurs most commonly between the age of ten and 50 years, with a slight male preponderance. ${ }^{1}$ Initially the tumours are eccentric, but eventually involve the whole width of the bone. ${ }^{1}$ It is locally aggressive, with a high recurrence rate if incompletely removed. ${ }^{1-3}$

\section{Case Report}

A 17-year-old male presented with a history of pain and swelling of the lower part of the left leg for eight months. Clinical examination showed an irregular swelling with a lobulated surface of variable consistency. The skin over the swelling was stretched and shiny. Movements of the ankle joint were normal. Plain radiographs showed an expansile, osteolytic lesion involving the lower half of the tibia, with a characteristic 'soap bubble appearance' (Fig. 1). A biopsy was performed and histology showed the features of an adamantinoma. A belowknee amputation was performed as there was insufficient normal tissue at the lower end of the tibia for wide resection and reconstruction. The patient returned four years later with pain and swelling over the lower part of the right thigh. He had no complaints regarding the previously affected limb. Plain radiographs of the right femur showed an osteolytic lesion in the distal metaphyseal region (Fig. 2). This was biopsied and histology showed the features of an adamantinoma (Fig. 3). A bone scan was performed but no other lesions were seen. Chest radiographs and CT scanning showed no evidence of pulmonary metastases.

Wide resection of the lesion and total knee replacement with a long-stemmed custommade prosthesis was advised, but the patient

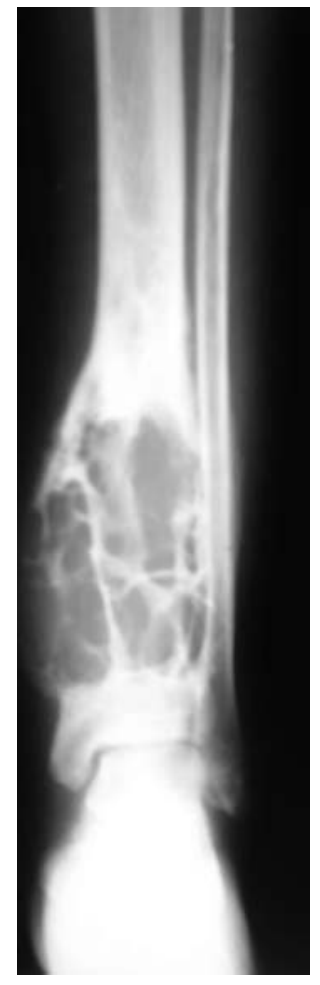

Fig. 1a

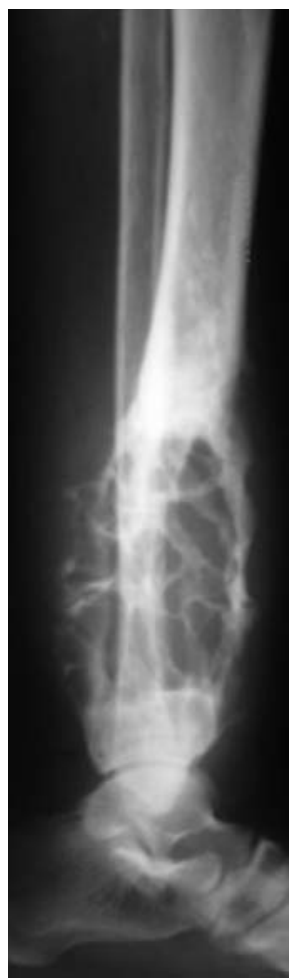

Fig. 1b a) Anteroposterior and b) lateral radiographs of the tibia showing the typical 'soap bubble' appearance. 


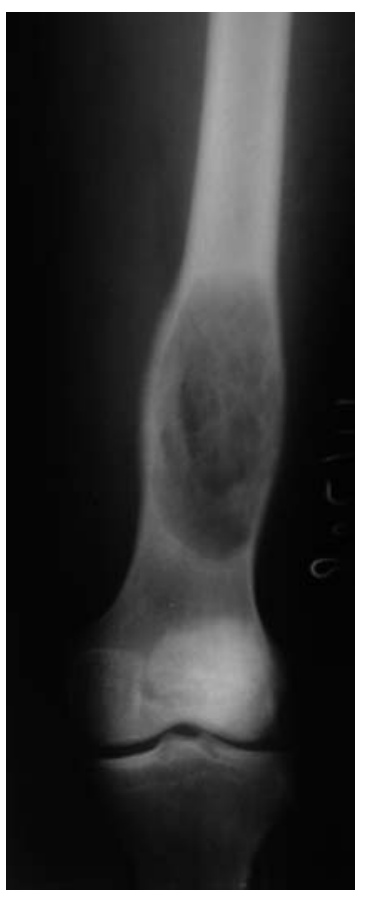

Fig. 2a

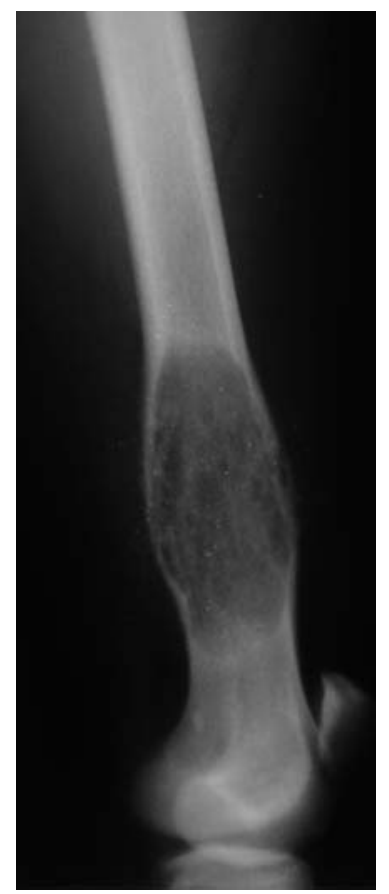

Fig. $2 b$
Radiographs showing a) an anteroposterior, and b) a lateral view of the lower end of the femur showing the osteolytic lesion.

was not able to afford this. As a result, an above-knee amputation had to be performed.

\section{Discussion}

Adamantinoma is a locally aggressive tumour notorious for recurrence following curettage. ${ }^{1-6}$ The incidence of recurrence is approximately $30 \%$ and of metastases between $10 \%$ and $20 \%{ }^{1,2,4}$ The most common site for metastasis is the lungs, with an incidence of around $15 \%{ }^{4}$ It can also metastasize to the lymph nodes. Skeletal metastasis is very rare.

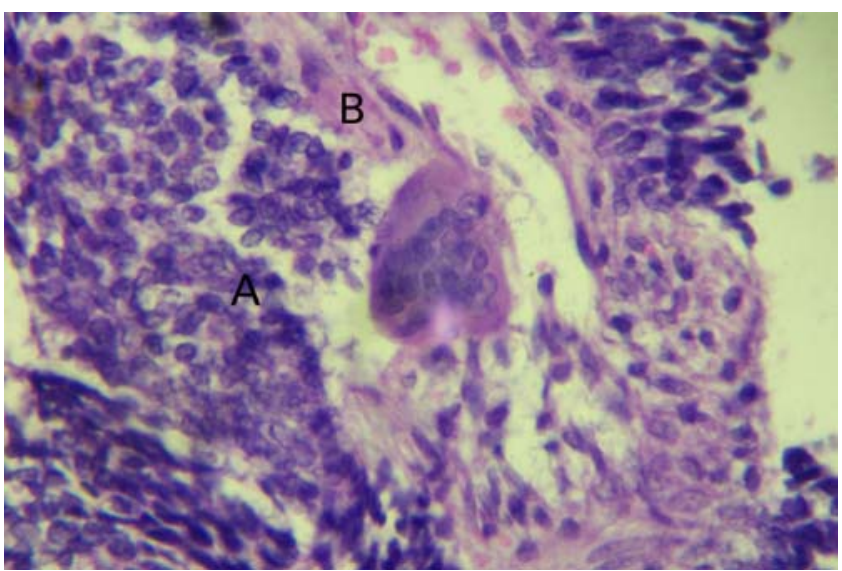

Fig. 3

Histopathological section of a specimen taken from the right femoral lesion showing the characteristic features of adamantinoma (dark basaloid cells (A) separated by dense fibrous stroma (B)).

This case was unusual as the patient developed a secondary lesion four years after resection of the primary tumour, and was symptom-free during the intervening period. There was no evidence of pulmonary metastases and no recurrence of tumour in the previously affected limb.

Even though a successful wide resection of this tumour may be carried out, long-term follow-up is mandatory.

No benefits in any form have been received or will be received from a commercial party related directly or indirectly to the subject of this article.

\section{References}

1. Stocker DJ, Saifuddin A. Diagnostic radiology In: Grainger RG, Allison DJ, Adam A, Dixon AL, eds. Grainger and Allison's bone tumours: malignant lesion. Fourth ed. Churchill Livingstone, 2001:1897-8.

2. Bullough P. Orthopaedic pathology. Fourth ed. Mosby, 442-4.

3. Resnick D, Kransdorf MJ. Bone and joint imaging. Third ed. Philadelphia: Elsevier Saunders, 2005:1190-2.

4. Damjanov I, Linder J. Anderson's pathology: primary bone tumours. Tenth ed. Mosby: 2561-2.

5. Levesque J, Marx RG, Bell RS, et al. A clinical guide to primary bone tumours. Williams and Wilkins, 1998:269-72.

6. Duthie RB, Bentley G. Mercer's orthopaedic surgery. Ninth ed. Jaypee, 2003:730-3. 